\title{
Decline of erythropoietin formation at continuous hypoxia is not due to feedback inhibition
}

\author{
KAI-UWE ECKARDT, JURGEN DITTMER, RAINER NEUMANN, \\ CHRISTIAN BAUER, AND ARMIN KURTZ \\ Department of Physiology, University of Zurich, CH-8057 Zurich, Switzerland
}

ECKARDT, KAI-UWE, JURgen DitTMER, RAINER NeUmanN, Christian Bauer, AND ARMin KuRTz. Decline of erythropoietin formation at continuous hypoxia is not due to feedback inhibition. Am. J. Physiol. 258 (Renal Fluid Electrolyte Physiol. 27): F1432-F1437, 1990. - Serum erythropoietin (EPO) levels in response to hypoxia are known to decline before an increase in blood oxygen carrying capacity. To define the possible mechanisms underlying this phenomenon, we have investigated 1) how renal EPO mRNA content and EPO production rate underlying the early kinetics of serum EPO levels change under different degrees of normobaric hypoxia, and 2) if a feedback inhibition of either EPO formation or EPO survival in the circulation exists by the hormone itself. We found that serum immunoreactive EPO levels in rats peaked after 12-h exposure to 7.5 or $9 \%$ oxygen $(2,949 \pm 600$ and $756 \pm 108 \mathrm{mU} / \mathrm{ml}$, respectively, mean $\pm \mathrm{SE}$ ) and declined to 29 and $64 \%$ of peak levels, respectively, after $36 \mathrm{~h}$ of hypoxia. EPO levels in response to $11.5 \%$ oxygen showed no consistent change between $12(122 \pm 21 \mathrm{mU} / \mathrm{ml}$, mean $\pm \mathrm{SE})$ and $36 \mathrm{~h}(182 \pm 35 \mathrm{mU} / \mathrm{ml})$ of hypoxia. The decline in EPO levels under severe hypoxia $\left(7.5 \% \mathrm{O}_{2}\right)$ was paralleled by a marked reduction in renal EPO mRNA content, indicating that it was primarily a result of diminished hormone production. The observed reductions in serum EPO after $36 \mathrm{~h}$ corresponded to preceding declines of calculated EPO production rates from 163- to 62 -fold $(7.5 \%$ $\mathrm{O}_{2}$ ) and 36- to 25 -fold $\left(9 \% \mathrm{O}_{2}\right.$ ) basal values. Application of 50 IU recombinant human EPO to rats $12 \mathrm{~h}, 6 \mathrm{~h}$, or immediately before hypoxic exposure to mimic the early increase in EPO levels did not affect endogenous EPO formation during a subsequent hypoxic exposure of $12 \mathrm{~h}$. These results indicate that the early decrease in EPO production at continuous hypoxia is not mediated by a negative feedback control through the effect of EPO on its production sites or target cells. Although the reduction in EPO production rate occurs independent of the amount of EPO produced, the magnitude of the decline appears to be related to the degree of the preceding stimulation.

normobaric hypoxia; kinetics; messenger RNA; half-life

TO ADAPT RED CELL MASS to oxygen demand of the organism, the glycoprotein hormone erythropoietin (EPO) is produced by the kidneys in inverse correlation with the oxygen content of arterial blood. Following acute hypoxic hypoxia, an increase in renal EPO mRNA has been demonstrated after $1 \mathrm{~h}(27)$, and circulating EPO increases within 1.5-2 h (27). Interestingly, it has been demonstrated that EPO levels reach maximal values after $6-24 \mathrm{~h}$ in rodents $(1,5,15,17,20,22,26,31)$ and within $48 \mathrm{~h}$ in humans $(1,24)$ and thereafter decline despite continued hypoxia. This early decrease in EPO levels occurs before red cell mass and therewith blood oxygen content has increased significantly $(1,17,20,26)$.

The mechanisms of this early decline have not been clarified but several hypotheses have been developed. Because circulating EPO levels are determined by the production rate and the clearance rate of the hormone, possible alterations in both have to be considered. On concept has early been proposed suggesting that EPC consumption might be increased by activated erythro poietic tissue (31). This has been supported by some clearance studies $(21,25)$ but others found no difference in EPO clearance rate in animals with hypo- or hyper plastic bone marrow (23) or any change in clearance rat after hypoxia (13). Alternatively, the proliferating ery thron might also exert a feedback inhibition on EPC production by mechanisms that would have to be inde pendent of circulating red cell mass. Support for thi concept comes from observations suggesting that EPO titers are higher in patients with bone marrow hypoplasio than in comparably anemic patients with active eryth ropoiesis $(9,28)$. Other factors that were considered to possibly reduce EPO production independent of eryth roid stimulation include a lowered blood oxygen affinity at prolonged hypoxia due to acidosis $(8,20,26,32)$ and malnutrition during continuous hypoxic stress. The lat ter appears, however, not to be the primary mechanism because EPO titers in fed and food-deprived rats were found to increase similarly on repeated hypoxia exposure (18). A further possibility is that EPO production is reduced as a result of a direct feedback inhibition through the hormone itself.

The present study in rats was therefore performed to address some of these possibilities and confine the potential mechanisms by which the early decline in EPO levels is brought about. First we tested whether the reduction of EPO levels is primarily caused by reduced hormone production. Because renal EPO production is determined by the amount of EPO mRNA $(4,27)$, we have compared the amounts of renal EPO mRNA before and after peak levels of serum EPO had been reached. Second, we examined whether EPO itself exerts a feedback inhibition, either through stimulation of the ery thron or a direct effect on its production sites. The effect of circulating EPO on its own production and secretion has, to our knowledge, so far only been addressed by Fried and co-workers $(13,14)$. In some $(13)$, but not al of their experiments (14), plasma erythropoietic bioactivity in rats that were both made hypoxic and injected 
with EPO approximated the sum of that in animals that received EPO only and that in animals made hypoxic without receiving exogenous EPO. However, in these studies EPO was administered for no longer than $3 \mathrm{~h}$ before the onset of hypoxia, and animals were then exposed to continuous hypoxia for only $3 \mathrm{~h}$. Because EPO levels have mainly been reported to decline $18 \mathrm{~h}$ or later after onset of hypoxia $(1,5,17,20,22)$, this chosen time interval might have been too short to see an effect that could account for the reduction of EPO levels normally occurring under continuous hypoxia. In this study we injected rats with recombinant human EPO (rhEPO) either $12 \mathrm{~h}, 6 \mathrm{~h}$, or immediately before a hypoxic exposure of $12 \mathrm{~h}$ to mimic the early increase in EPO levels and compared the endogenous EPO production following the hypoxia with that in untreated animals. Finally, we estimated the kinetics of EPO production rates underlying the changes in serum EPO levels and related alterations in the production rate to the degree of hypoxia.

Our findings indicate that the decline in serum EPO levels results primarily from a decrease in EPO production rate. This decrease appears not to be mediated by the hormone itself and occurs independently of the amount of EPO produced, whereas the rate of decline seems to be related to the degree of the preceding stimulation.

\section{MATERIALS AND METHODS}

Animals. Zur:SIV strain male rats (body wt 250-300 g) were used in this study.

Hypoxic stimulation of EPO production. Normobaric arterial hypoxia was used as stimulus for EPO formation. To this end animals were exposed to an atmosphere low in oxygen $\left(7.5,9\right.$, and $\left.11.5 \% \mathrm{O}_{2}\right)$ with the use of a chamber gassed with appropriate mixtures of normal air and nitrogen. Groups of five to seven animals were simultaneously exposed to hypoxia for varying time periods from 3 to $36 \mathrm{~h}$. At the onset of hypoxia the chamber was flushed to achieve the respective oxygen tensions within $\sim 25$ min. Oxygen content of the gas mixture in the chamber was checked by means of a Bacharach Fyrite oxygen indicator (Bacharach, Pittsburgh, PA).

Within $15 \mathrm{~min}$ after the end of hypoxic exposure animals were bled from the dorsal aorta under ether anesthesia for determination of serum EPO levels.

Experiments with exogenous application of EPO. To assess the importance of circulating EPO for the early decline in serum EPO levels under continuous hypoxia (see RESULTS), rhEPO was administered to rats $12 \mathrm{~h}, 6$ $\mathrm{h}$, or immediately before a subsequent hypoxic exposure of $12 \mathrm{~h}\left(7.5 \% \mathrm{O}_{2}\right)$. Fifty international units rhEPO were dissolved in saline and injected via a tail vein under light methofane anesthesia. Control animals were injected with saline only and simultaneously exposed to hypoxia. To estimate the amount of residual rhEPO in serum after the end of the hypoxic exposure, additional animals were injected with the same amount of rhEPO, but not exposed to hypoxia, and bled 12,18 , and $24 \mathrm{~h}$ after the injection.

Determination of EPO clearance rate. Calculation of EPO production rates from the change in serum EPO levels requires an estimate of EPO clearance rate. To determine the disappearance rate of homologous EPO in the rat, clearance studies were carried out in three animals. After anesthesia with $100 \mathrm{mg} / \mathrm{kg}$ body wt 5-ethyl 5-(1'-methylpropyl)-2-thiobarbituric acid (Inactin, BykGulden, Constance, FRG), these animals were artifically ventilated by means of a Harvard small animal respirato $\left(25 \% \mathrm{O}_{2}, 75\right.$ strokes/min, stroke volume $\left.2 \mathrm{ml}\right)$ to avoid hypoxic stimulation of endogenous EPO formation EPO-enriched rat serum containing 3,500 $\mathrm{mU}$ immuno reactive (ir) $\mathrm{EPO} / \mathrm{ml}$ was obtained from hypoxic dono animals and injected intravenously via a femoral cathetef at a dose of $20 \mathrm{U} \mathrm{EPO} / \mathrm{kg}$ body wt. Before, 2 min after, and at subsequent hourly intervals after the injection $150 \mu \mathrm{l}$ of blood were withdrawn from a catheter in the femoral artery for determination of serum EPO (see below).

Figure 1 demonstrates the decline in serum irEPO values. One hour following the administration, value fitted a single exponential regression curve: log serum irEPO $(\mathrm{mU} / \mathrm{ml})=-0.0027 \times$ time $(\mathrm{min})+2.36(r=$ -0.94). The half-life time of disappearance resultin from this slope is $110 \mathrm{~min}$. This value is in accordance with a previous study, estimating an elimination half life of $86 \mathrm{~min}$ from the decline of serum levels within 2 $h$ after application of homologous EPO to rats (30) and more recent investigations, determining the elimination half-life of iodinated rhEPO in the rat between 108 (16) and $180 \mathrm{~min}(29)$. To assess whether the clearance rat of EPO is different in normoxic and hypoxic animals the recovery of intravenously injected iodinated rhEPO ( $\left.{ }^{125} \mathrm{I}-\mathrm{rhEPO}\right)$ (Amersham International, Buckingham shire, UK) in serum of animals exposed to normoxia and

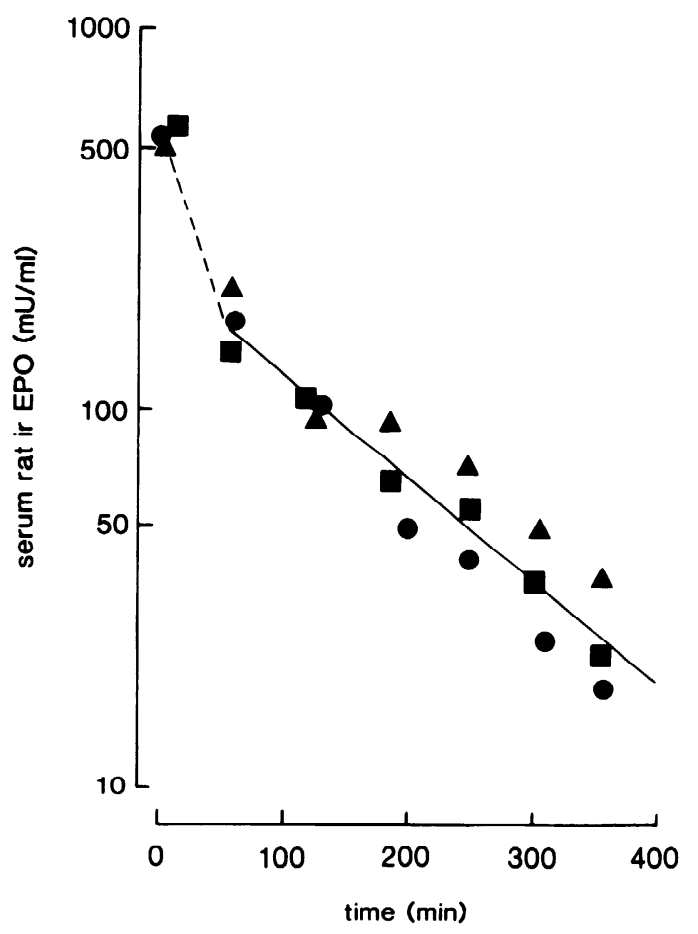

FIG. 1. Serum clearance of irEPO in 3 rats injected with homologous EPO at a concentration of $20 \mathrm{U} / \mathrm{kg}$ body wt. The individual basal value was subtracted from the serum value. After $1 \mathrm{~h}$, values fitted a single exponential regression line: $\log$ serum irEPO $(\mathrm{mU} / \mathrm{ml})=-0.0027 \times$ time $(\mathrm{min})+2.36, r=-0.94$. The resulting $t_{1 / 2}$ is $110 \mathrm{~min}$. 
hypoxia was compared. Under light methofane anesthesia 10 rats were injected via a tail vein with 120,650 counts/min (cpm) of ${ }^{125} \mathrm{I}-\mathrm{EPO}$ (sp act, $710 \mathrm{Ci} / \mathrm{mmol}$ ) dissolved in $0.9 \% \mathrm{NaCl}$ containing $0.1 \%$ bovine serum albumin. Five animals each were then immediately exposed to hypoxia $\left(7.5 \% \mathrm{O}_{2}\right)$ for $5 \mathrm{~h}$ or kept at room atmosphere. Five hours fifteen minutes after the injection, animals in both groups were bled from the dorsal aorta for determinations of residual radioactivity. Table 1 illustrates that no evidence was obtained for a change of EPO clearance rate under hypoxia.

Determination of EPO. EPO was determined by radioimmunoassay as previously described (11) with the use of an antiserum raised against rhEPO and ${ }^{125}$ I-rhEPO as tracer. The antiserum is cross-reactive with rat EPO but displacement curves for rat and human EPO are different. Therefore different standard preparations were used to determine human or rat EPO concentrations. 1) Serial dilutions of a rat serum pool, enriched in EPO by exposing donor animals to hypoxia, were used as standards for determinations of rat EPO. This serum pool was previously calibrated against the Second International Reference Preparation (II-IRP, World Health Organization) in the polycythemic mouse bioassay (11). 2) In those assays designed to estimate the amount of human EPO after injection of rhEPO to rats, the standard curve consisted of standard amounts of human EPO (II-IRP) that were added to normal rat serum. 3) In experiments carried out to determine endogenous production of rat EPO in hypoxic animals injected with rhEPO, the average concentration of residual human EPO that was determined in animals injected with rhEPO but not exposed to hypoxia was added to each standard dilution of the rat serum pool.

\section{Northern Blot Analysis}

Northern blot analysis of renal EPO mRNA was performed in normotoxic animals and animals exposed to $7.5 \% \mathrm{O}_{2}$ for 8 or $36 \mathrm{~h}$. For control EPO mRNA was simultaneously analyzed from IW32 cells (7).

RNA isolation. Total RNA was isolated from rat kidneys or IW32 cells as described (6) and further purified by precipitation in a $\mathrm{LiCl}$-urea-containing solution (2). Poly $(\mathrm{A})^{+}$RNA was isolated by chromatographic separation using oligo-(dT) cellulose spun columns (Pharmacia, Uppsala, Sweden) following the instructions of the supplier.

TABLE 1. Recovery of ${ }^{125} I$-rhEPO in normoxic

$\left(21 \% \mathrm{O}_{2}\right)$ and hypoxic $\left(7.5 \% \mathrm{O}_{2}\right)$ rats $5.25 \mathrm{~h}$

after intravenous injection

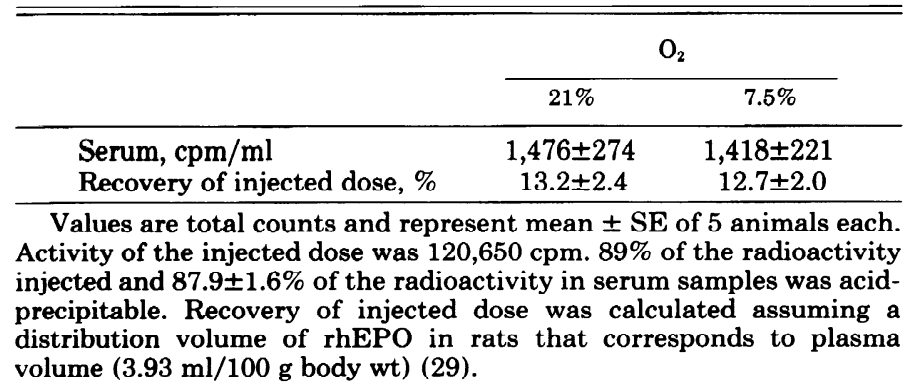

Northern blot. RNA sample preparation and electrophoresis were performed as described (12). The agarose concentration of the gel was $1 \%$. After running at constant voltage $(90 \mathrm{~V})$ the gel was first soaked in $1 \ngtr$ standard sodium citrate (SSC) $(0.15 \mathrm{M} \mathrm{NaCl}, 0.015 \mathrm{M}$ sodium citrate, $\mathrm{pH} 7.0$ ) containing $0.05 \mathrm{~N} \mathrm{NaOH}$ for 10 min before equilibration with $10 \times \mathrm{SSC}$. Blotting was performed onto Hybond $\mathrm{N}$ (Amersham) for at least $18 \mathrm{~h}$ After blotting, the filter was baked for $30 \mathrm{~min}$ at $80^{\circ} \mathrm{C}$.

Hybridization. The filter was rehydrated in $2 \times \mathrm{SSC}$ and prehybridized overnight at $42^{\circ} \mathrm{C}$ in a solution containing $50 \%$ formamide, $4 \times$ SSC, $5 \times$ Denhardt's solution $(0.1 \%$ polyvinylpyrrolidone $360,0.1 \%$ Ficoll 400 , $0.1 \%$ bovine serum albumin), $25 \mathrm{mM}$ sodium phosphate (pH 6.5), $300 \mu \mathrm{g} / \mathrm{ml}$ sheared denatured salmon sperm DNA, and $0.1 \%$ sodium dodecyl sulfate (SDS). Three hundred microliters of the prehybridization solution were used per square centimeter filter. EPO-specific mRNA was detected by hybridization with pDB2-5, a plasmid containing the BglII-fragment of the murine EPO gene, inserted into the BamHI site of the plasmid vector PUO 19. The plasmid was labeled with $\left[{ }^{32} \mathrm{P}\right] \mathrm{dCTP}$ (Amersham) to a specific activity of $\sim 10^{8} \mathrm{cpm} / \mu \mathrm{g}$ DNA by the oligo primed labeling procedure with the use of the multiprime kit (Amersham). After labeling, the DNA was purified by spun-column chromatography using Sephadex G-50 (Pharmacia). Hybridization was performed overnight at $42^{\circ} \mathrm{C}$ in the same solution as described for prehybridization but with $3 \times$ Denhardt's and supplemented with $10 \%$ dextran sulfate and $10 \mathrm{ng} / \mathrm{ml}$ labeled EPO probe. After hybridization the filter was washed once in $2 \times \mathrm{SSC}$ for $5 \mathrm{~min}$ at $R T$, once in $0.2 \times$ $\mathrm{SSC}$ for $5 \mathrm{~min}$ at $R T$, twice in $0.1 \times \mathrm{SSC}$ for $15 \mathrm{~min}$ at $61^{\circ} \mathrm{C}$ and once in $2 \times \mathrm{SSC}$ for $5 \mathrm{~min}$ at $R T$. To each solution SDS was added to a final concentration of $0.1 \%$. After drying, the filter was exposed to Dupont Cronex 4 (Du Pont de Nemours, Bad Homburg, FRG). For control, hybridized EPO probe was removed and filters were reprobed with an $\alpha$-tubulin probe under the conditions described above.

\section{Estimation of EPO Production Rates.}

Relative increases in the production rates of EPO were calculated for different time points $(t)$ of hypoxic exposure from serum EPO values according to the equation

$$
\begin{aligned}
& \mathrm{PR}_{t} \div \mathrm{PR}_{0}=\left(\Delta \mathrm{EPO}_{t}+\ln 2 \div t_{1 / 2}\right.\left.\times \mathrm{EPO}_{t}\right) \\
& \div\left(\ln 2 \div t_{1 / 2} \times \mathrm{EPO}_{0}\right)
\end{aligned}
$$

$\mathrm{EPO}_{0}$ and $\mathrm{EPO}_{t}$ are the basal serum level and the serum level at the respective time point, $\mathrm{PR}_{0}$ and $\mathrm{PR}_{t}$ are the basal production rate and the production rate at the respective time point, and $\mathrm{PR}_{t} / \mathrm{PR}_{0}$ is the relative increase in EPO production rate. $\triangle \mathrm{EPO}_{t}$ is the increase of serum EPO at the respective time point, as assessed by linear interpolation between two sucessive serum levels. $\left(\ln 2 / t_{1 / 2} \times\right.$ EPO) is the clearance of EPO and the half-life $\left(t_{1 / 2}\right)$ was assumed to be $110 \mathrm{~min}$, as averaged from the EPO clearance experiments. 


\section{RESULTS}

Figure 2, top, demonstrates the kinetics of serum irEPO values in rats exposed to three different degrees of normobaric hypoxia $\left(7.5,9\right.$, and $\left.11.5 \% \mathrm{O}_{2}\right)$ for up to $36 \mathrm{~h}$. Under 7.5 and $9 \% \mathrm{O}_{2}$, EPO levels peaked after 12 $\mathrm{h}$ of exposure and declined to 29 and $64 \%$ of these values, respectively, after $36 \mathrm{~h}$ of hypoxia. In response to $11.5 \%$ $\mathrm{O}_{2}$, EPO values approximated a plateau between 12 and $36 \mathrm{~h}$, with no sustained reduction during this phase.

Employing the average half-life time of $110 \mathrm{~min}$, as determined from clearance experiments (Fig. 1), the relative production rates of EPO in response to the different hypoxic stimuli were calculated from serum irEPO levels and are demonstrated in Fig. 2, bottom. It becomes obvious that the peaks in serum EPO levels are preceded by peak levels of the production rate by $\sim 3 \mathrm{~h}$.

To determine whether the decline in EPO levels after $12 \mathrm{~h}$ of continuous hypoxia, which was most prominent under severe hypoxic stress $\left(7.5 \% \mathrm{O}_{2}\right)$, might be induced by the previous increase in EPO levels, rhEPO was administered to rats at different times before the hypoxic exposure. Because the distribution volume of human EPO in rats has been found to correspond to plasma volume (29), a dose of $50 \mathrm{U}$ per animal was used to
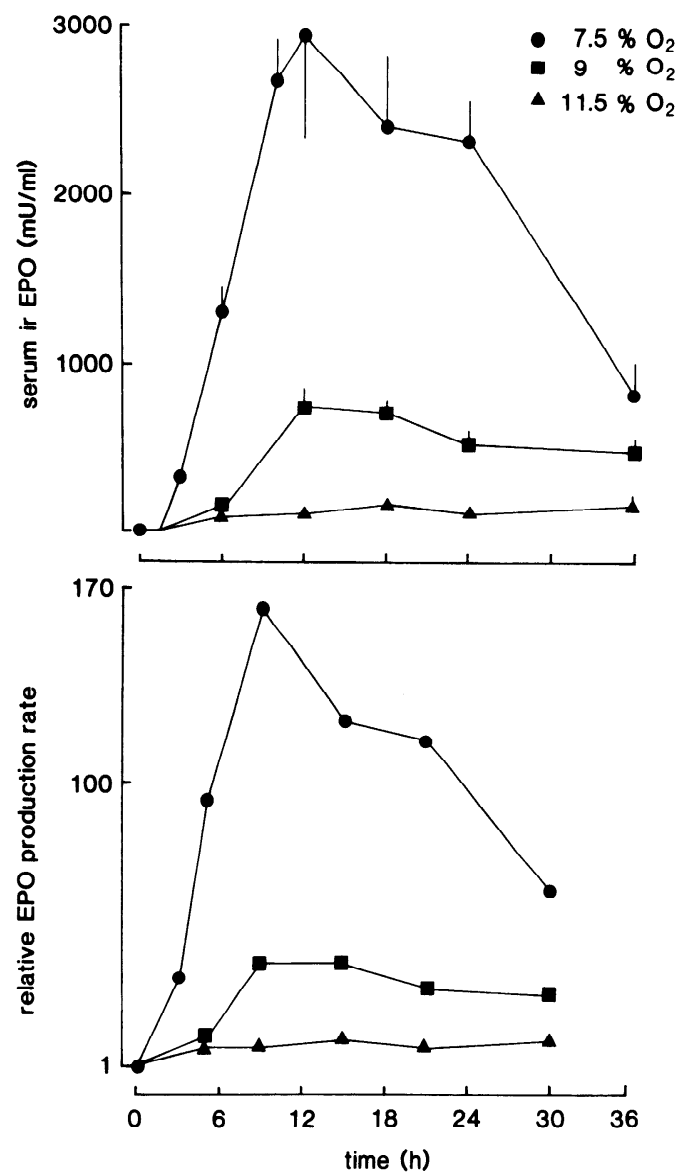

FIG. 2. Time-dependent change in serum irEPO (top) and underlying alterations in relative EPO production rates (bottom) in rats exposed to 3 different degrees of normobaric hypoxia. Serum irEPO values are means $\pm \mathrm{SE}$ for 5 animals each, except a 12 -h value for $7.5 \%$ $\mathrm{O}_{2}(n=13)$. Relative production rates were calculated from increase in serum EPO levels, assuming a constant EPO half-life of $110 \mathrm{~min}$ (see RESULTS and Fig. 4). achieve peak serum levels of $\sim 5,000 \mathrm{mU} / \mathrm{ml}$ (assuming a plasma volume of $3.93 \mathrm{ml} / 100 \mathrm{~g}$ body wt; see Ref. 29 ). This value even exceeds the levels of endogenous EPO under severe hypoxia (7.5\%). Figure 3, bottom, gives the residual levels of the administered human EPO found 24,18 , and $12 \mathrm{~h}$ after the injection in animals that were not exposed to hypoxia. Figure 3 , top, demonstrates levels of endogenous rat irEPO in animals exposed for $12 \mathrm{~h}$ to hypoxia $\left(7.5 \% \mathrm{O}_{2}\right)$ either immediately after or 6 and 12 $h$ after the injection of rhEPO or saline. It is obvious that the administration of rhEPO at none of the three time points had any effect on endogenous EPO levels when compared with untreated controls that were simultaneously exposed to hypoxia.

To investigate whether the decline in serum EPO under continuous hypoxia was paralleled by changes in renal EPO mRNA content, Northern blot analysis for EPO mRNA was performed on kidney homogenates obtained from animals exposed to $7.5 \% \mathrm{O}_{2}$ for 8 or $36 \mathrm{~h}$. The result is illustrated in Fig. 4. Whereas no signal was detectable in normoxic animals, EPO mRNA increased markedly after $8 \mathrm{~h}$ of hypoxia. After $36 \mathrm{~h}$ EPO mRNA

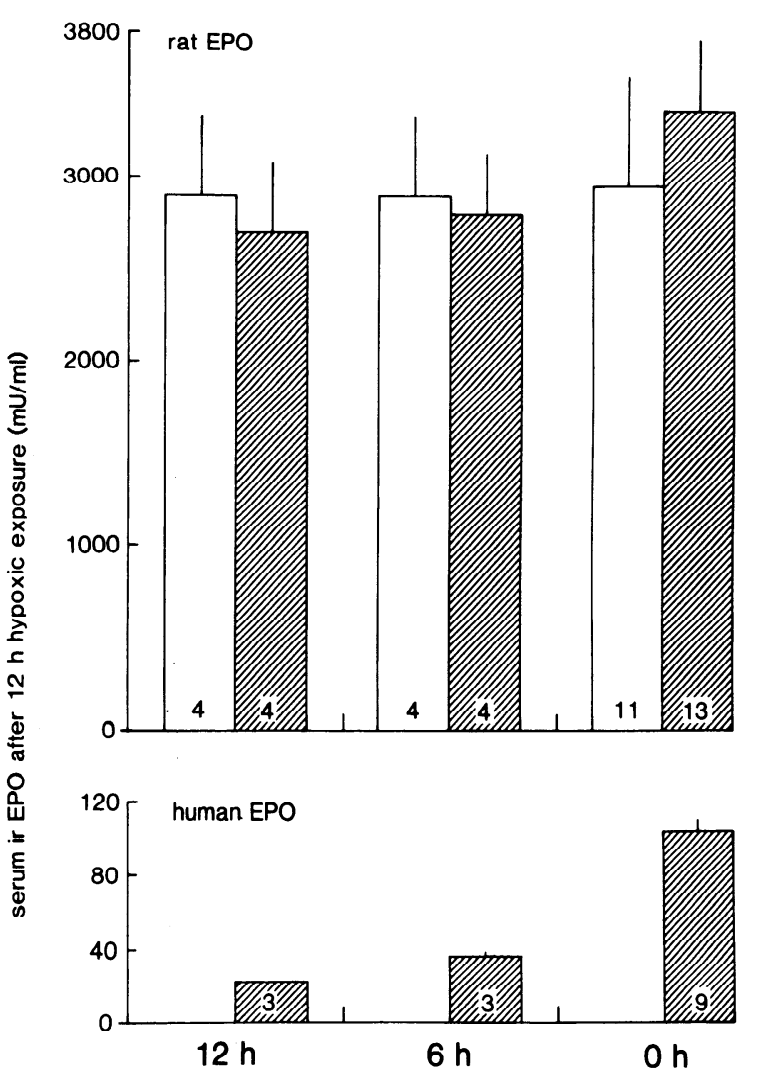

time interval between rh EPO injection and onset of hypoxia

FIG. 3. Serum irEPO levels in rats treated with $50 \mathrm{U}$ recombinant human EPO at different time points before exposure to $12 \mathrm{~h}$ hypoxia (hatched bars) and in control animals injected with saline (open bars) (mean $\pm \mathrm{SE}$, nos. in bars are numbers of animals). Residual levels of human EPO at time points corresponding to end of hypoxic exposure (bottom) were assessed in animals not exposed to hypoxia. Note different scales in both panels. Concentrations of human EPO (bottom) were measured against a standard curve consisting of human EPO (II-IRP) dissolved in normal rat serum. Concentrations of endogenous rat EPO (top) were measured against standard curves consisting of rat EPO with the respective average concentration of residual human EPO added to each standard point. 

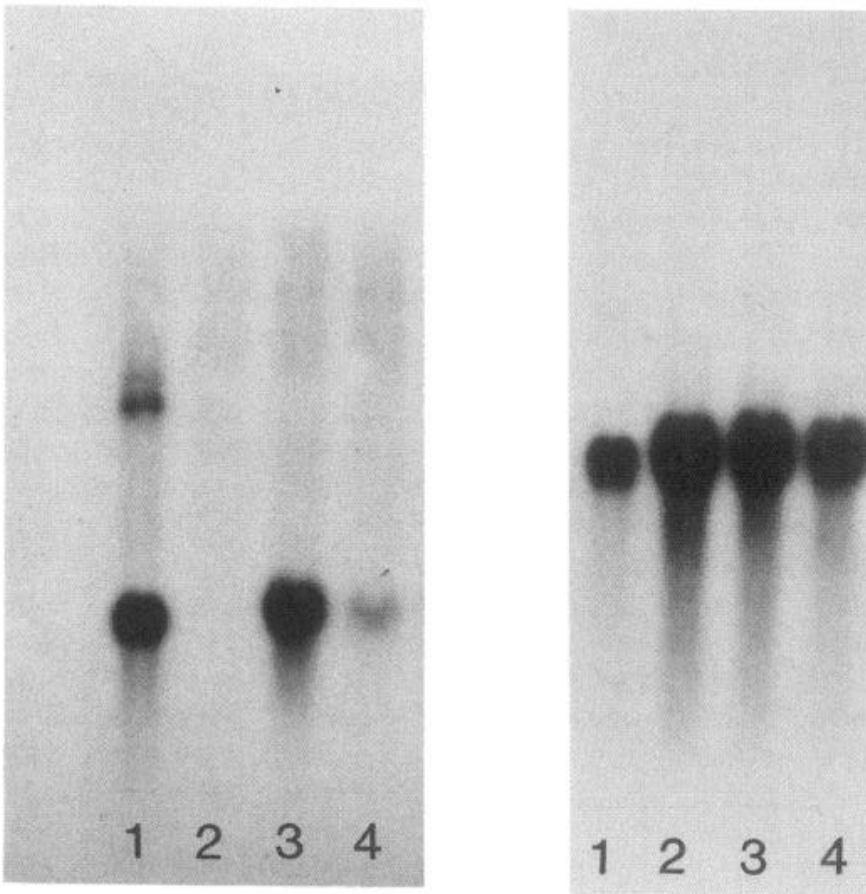

FIG. 4. Northern blot analysis of poly $(A)^{+}$RNA isolated from IW32 (lane 1), and from kidney extracts of normoxic rats (lane 2) and rats exposed to $7.5 \% \mathrm{O}_{2}$ for 8 (lane 3) or $36 \mathrm{~h}$ (lane 4); (lane 1: $5 \mu \mathrm{g}$ RNA, lanes 2-4: $20 \mu \mathrm{g}$ RNA). Left: hybridization with an EPO probe. Right: rehybridization with an $\alpha$-tubulin probe after stripping the blot.

was still detectable, but clearly reduced. Since EPO formation has been shown to be mainly determined by the amount of EPO mRNA $(4,27)$, this result indicates that the reduction in EPO levels is primarily due to diminished hormone production.

\section{DISCUSSION}

The early kinetics of serum irEPO under severe normobaric hypoxia $\left(7.5\right.$ and $9 \% \mathrm{O}_{2}$ ) as determined in the present study (Fig. 2, top), are in accordance with previous studies employing hypobaric $(1,5,17,20,22,24$, $26,31)$ or also normobaric hypoxia (22). Although the reported time intervals after which peak serum levels were reached are variable, it appears to be a consistent finding that EPO titers do not remain at the elevated levels that are reached early upon hypoxia, but despite continued hypoxic exposure decline to values that are still above base line, but severalfold below peak concentrations.

The observation in the present investigation, that this decline in serum EPO is accompanied by a marked reduction of renal EPO mRNA content (Fig. 4), provides evidence that it is primarily due to a reduction in EPO production, rather than to enhanced hormone clearance or consumption. Interestingly, the pattern of EPO production rates, which were calculated under the assumption of a constant EPO disappearance rate (Fig. 2, bottom), resembles the time course of the amount of EPO extractable from kidneys under continuous hypoxia, as shown by Jelkmann (17) and Caro and Erslev (5). Peak levels of kidney EPO preceded peak concentrations of serum EPO, as did the calculated production rates. The fall in kidney EPO, which parallels the decline in serum levels, provides additional evidence for a reduction in EPO formation.

Regarding the mechanisms by which the reduction in EPO production is mediated, we tested whether an increase in serum EPO due to exogenous administration of the hormone affects hypoxia-induced EPO formation. EPO was injected to achieve serum levels that even exceeded endogenous EPO levels preceding the decline in EPO production. Nevertheless, the endogenous EPO formation in response to subsequent hypoxic stimulation was unaffected (Fig. 3). This suggests that no feedback inhibition exists through the effect of circulating EPO on its production sites or target cells.

In view of the marked increases in EPO production rates after the onset of hypoxia (Fig. 2, bottom) one might further consider an exhaustion of production capacity. However, when the temporal patterns of EPO production rates under different hypoxic stimuli are compared (Fig. 2, bottom), it can be estimated from the areas under the curve that the decline in EPO production rate occurred independently of the amount of EPO produced. Thus, under $7.5 \% \quad \mathrm{O}_{2}$, twice as much EPO had been produced before production rates started to decline than under $9 \% \mathrm{O}_{2}$.

Some investigators suggested a possible role of improved peripheral oxygenation through a rightward shift of the oxygen binding curve for the early decline in EPO production $(8,20,26,32)$. Direct studies on the effect of oxygen affinity of hemoglobin on EPO formation suggest, however, that its relative role decreases with increasing severity of hypoxia (19). In contrast, in our study the absolute and relative decline in EPO production rates as well as the rate of decline were more pronounced with increasing degrees of hypoxia (Fig. 2, bottom). Furthermore, the quantitative effect of changes in oxygen affinity of hemoglobin is less than the observed decline seen in our investigation (19).

Apart from systemic adaptations to hypoxia, the decline of EPO formation could also be related to alterations in renal hemodynamics. Under severe hypoxia a relative decrease in the glomerular filtration rate in comparison with renal blood flow has been reported in some studies (see Ref. 3). This might reduce the workload of the kidney and thereby decrease the ratio between oxygen consumption and oxygen supply, which is thought to determine EPO production rate. However, we have recently shown that the reduction of proximal tubular sodium reabsorption, required to inhibit EPO formation, amounts to $\sim 20 \%$ of the filtered load (11) and this exceeds changes observed under hypoxia.

Finally, an adaptation to hypoxia could also occur at the cellular level of EPO formation, and might directly affect the transcription rate of the EPO gene, or alternatively, decrease the stability of EPO mRNA, thereby reducing hormone production. Definite differentiation between these possibilities will await isolation of the renal cells producing EPO.

The rabbit antiserum against EPO used in the radioimmunossay and recombinant human EPO was a gift from Drs. P. Hirth and P. Scigalla, Boehringer, Mannheim, FRG. The plasmid pDB2-5 was 
kindly provided by Dr. C.B. Shoemaker, Genetics Insitute, Boston, MA. The $\alpha$-tubulin probe was kindly provided by Dr. L. Tannahill, London, UK. The expert technical assistance of U. Bolliger is gratefully acknowledged. W. Gehret did the artwork.

The study was financially supported in part by the Swiss National Science Foundation (grant No. 3.165.88) and the Hartmann Müller Stiftung für Medizinische Forschung. K.-U. Eckardt was a recipient of a fellowship from the German Research Foundation, and R. Neumann was supported by a fellowship from the European Molecular Biology Organization.

Received 18 September 1989; accepted in final form 21 November 1989.

\section{REFERENCES}

1. AbBrecht, P. H., AND J. K. LitTell. Plasma erythropoietin in men and mice during acclimatization to different altitudes. J. Appl. Physiol. 32: 54-58, 1972.

2. Auffray, C., AND F. Rougeon. Purification of mouse immunoglobulin heavy-chain messenger RNAs from total myeloma tumor RNA. Eur. J. Biochem. 107: 303-314, 1980.

3. BAUER, Ch., AND A. KURTz. Oxygen sensing in the kidney and its relation to erythropoietin production. Annu. Rev. Physiol. 51: 845856, 1989.

4. Bondurant, M. C., AND M. J. Koury. Anemia induces accumulation of erythropoietin mRNA in the kidney and liver. Mol. Cell. Biol. 6: 2731-2733, 1986.

5. CARo, J., AND A. J. Erslev. Biologic and immunologic erythropoietin in extracts from hypoxic whole rat kidneys and in their glomerular and tubular fractions. J. Lab. Clin. Med. 103: 922-931, 1984.

6. Chirgwin, J. M., A. E. Przybyla, R. J. MacDonald, and W. J. RUTTER. Isolation of biologically active ribonucleic acid from sources enriched in ribonuclease. Biochemistry 18: 5294-5299, 1979.

7. Choppin, J. C., C. Lacombe, N. Casadevall, O. MulleR, P. TAMBOURIN, AND B. VARET. Characterization of erythropoietin produced by IW32 murine erythroleukemia cells. Blood 64: 341347,1984

8. Cohen, R. A., M. E. Miller, J. F. Garcia, G. Moccia, and E. P. CRONKITE. Regulatory mechanisms of erythropoietin production: effects of hypoxemia and hypercarbia. Exp. Hematol. 9: 513$521,1981$.

9. De KleRK, G., P. C. J. Rosengarten, R. J. W. M. Vet, AND R. GouDSMIT. Serum erythropoietin (ESF) titers in anemia. Blood 58: 1164-1170, 1981.

10. ECKARDT, K.-U., A. KURTz, AND C. BAUER. Regulation of erythropoietin formation is related to proximal tubular function. Am. J. Physiol. 256 (Renal Fluid Electrolyte Physiol. 25): F942-F947, 1989.

11. EckardT, K.-U., A. Kurtz, P. Hirth, P. Scigalla, L. WieczoREK, AND C. BAUER. Evaluation of the stability of human erythropoietin in samples for radioimmunoassay. Klin. Wochenschr. 66: 241-245, 1988.

12. Fourney, R. M., J. Miyakoski, R. S. Day III, And M. C. PaterSON. Northern blotting: efficient RNA staining and transfer. Focus 10: 5-7, 1988 .

13. Fried, W., AND J. Barone-Varelas. Regulation of the plasma erythropoietin level in hypoxic rats. Exp. Hematol. 12: 706-711, 1984.

14. Fried, W., J. Barone-Varelas, T. Barone, and M. HelfgotT.
Extraction of erythropoietin from kidneys. Exp. Hematol. 8: 41$50,1980$.

15. Fried, W., C. Johnson, AND P. Heller. Observations on regulation of erythropoiesis during prolonged periods of hypoxia. Blood 36: 607-616, 1970.

16. Fukuda, M. N., H. SASAKi, L. Lopez, and M. FukUda. Survivaof recombinant erythropoietin in the circulation: the role of car bohydrates. Blood 73: 84-89, 1989.

17. JelkmanN, W. Temporal patterns of erythropoietin titers in kidney tissue during hypoxic hypoxia. Pfluegers Arch. 393: 88-91 1982.

18. Jelkmann, W., A. Kurtz, AND C. Bauer. Effects of fasting on the hypoxia-induced erythropoietin production in rats. Pfluegers Arch. 396: 174-175, 1983.

19. LEChERMANN, B., AND W. JeLKMANN. Erythropoietin production in normoxic and hypoxic rats with increased blood oxygen affinity Resp. Physiol. 60: 1-8, 1985.

20. Miller, M. E., AND D. How ARD. Modulation of erythropoietin concentrations by manipulation of hypercarbia. Blood Cells 5: 389 403, 1979.

21. Mirand, E. A., A. S. Gordon, E. D. Zanjani, T. E. Bennett AND T. G. P. MURPHY. Disappearance of exogenous erythropoietin (ESF) from the blood of germ free mice. Proc. Soc. Exp. Biol. Med. 139: 161-164, 1971.

22. Mirand, E. A., ANd T. C. Prentice. Presence of plasma eryth ropoietin in hypoxic rats with or without kidney(s) and/or spleen Proc. Soc. Exp. Biol. Med. 96: 49-51, 1957.

23. NAETS, J. P., AND M. WITTEK. Erythropoietic activity of marrow and disappearance rate of erythropoietin in the rat. Am. J. Physiol. 217: 297-301, 1969.

24. Reynafarje, C., J. Ramos, J. Faura, and D. Villavicencio. Humoral control of erythropoietic activity in man during and after altitude exposure. Proc. Soc. Exp. Biol. Med. 116: 649-658, 1964.

25. RUSSELL, E. S., AND G. KeIGHLEY. The relation between eryth ropoiesis and plasma erythropoietin levels in normal and geneti cally anaemic mice during prolonged hypoxia or after whole-body irradiation. Br. J. Haematol. 22: 437-452, 1972.

26. Schooley, J. C., AND L. J. MahlmanN. Hypoxia and the initiation of erythropoietin production. Blood Cells 1: 429-448, 1975.

27. Schuster, S. J., J. H. Wilson, A. J. Erslev, and J. Caro. Physiologic regulation and tissue localization of renal erythropoi etin messenger RNA. Blood 70: 316-381, 1987.

28. Sherwood, J. B., E. Goldwasser, R. Chilcote, L. D. Carmi CHAEL, AND R. L. NAGEL. Sickle cell anemia patients have low erythropoietin levels for their degree of anemia. Blood 67: 46-49 1986.

29. SpIVAK, J. L., AND B. B. Hogans. The in vivo metabolism of recombinant human erythropoietin in the rat. Blood 73: 90-99, 1989.

30. Steinberg, S. E., J. F. Garcia, G. R. Matzke, and J. MladenovIC. Erythropoietin kinetics in rats: generation and clearance Blood 67: 646-649, 1986.

31. STOHLMAN, F., AND G. BRECHER. Humoral regulation of erythropoiesis V. Relationship of plasma erythropoietine level to bone marrow activity. Proc. Soc. Exp. Biol. Med. 100: 40-43, 1959.

32. Wolf-Priessnitz, J., J. C. SChOoley, and L. J. MahlmanN. Inihibition of erythropoietin production in unanesthetized rabbits exposed to an acute hypoxic-hypercapnic environment. Blood 52 : 153-162, 1978. 